\title{
Development and validation of an RNA binding protein-associated prognostic model for hepatocellular carcinoma
}

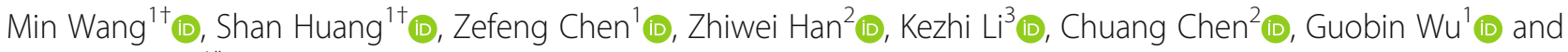
Yinnong Zhao ${ }^{1 *}$ (D)

\begin{abstract}
Background: Hepatocellular carcinoma (HCC) is among the deadliest forms of cancer. While RNA-binding proteins (RBPs) have been shown to be key regulators of oncogenesis and tumor progression, their dysregulation in the context of HCC remains to be fully characterized.

Methods: Data from the Cancer Genome Atlas - liver HCC (TCGA-LIHC) database were downloaded and analyzed in order to identify RBPs that were differentially expressed in HCC tumors relative to healthy normal tissues. Functional enrichment analyses of these RBPs were then conducted using the GO and KEGG databases to understand their mechanistic roles. Central hub RBPs associated with HCC patient prognosis were then detected through Cox regression analyses, and were incorporated into a prognostic model. The prognostic value of this model was then assessed through the use of Kaplan-Meier curves, time-related ROC analyses, univariate and multivariate Cox regression analyses, and nomograms. Lastly, the relationship between individual hub RBPs and HCC patient overall survival (OS) was evaluated using Kaplan-Meier curves. Finally, find protein-coding genes (PCGs) related to hub RBPs were used to construct a hub RBP-PCG co-expression network.

Results: In total, we identified 81 RBPs that were differentially expressed in HCC tumors relative to healthy tissues (54 upregulated, 27 downregulated). Seven prognostically-relevant hub RBPs (SMG5, BOP1, LIN28B, RNF17, ANG, $\angle A R P 1 B$, and NROB1) were then used to generate a prognostic model, after which HCC patients were separated into high- and low-risk groups based upon resultant risk score values. In both the training and test datasets, we found that high-risk HCC patients exhibited decreased OS relative to low-risk patients, with time-dependent area under the ROC curve values of 0.801 and 0.676 , respectively. This model thus exhibited good prognostic performance. We additionally generated a prognostic nomogram based upon these seven hub RBPs and found that four other genes were significantly correlated with OS.
\end{abstract}

Conclusion: We herein identified a seven RBP signature that can reliably be used to predict HCC patient OS, underscoring the prognostic relevance of these genes.

Keywords: RNA binding protein, Hepatocellular carcinoma, Prognosis, Comprehensive bioinformatics analysis

\footnotetext{
* Correspondence: zhaoyinnong@gxmu.edu.cn

${ }^{\dagger}$ Min Wang and Shan Huang contributed equally to this work.

${ }^{1}$ Department of Hepatobiliary Surgery, Guangxi Medical University Cancer

Hospital, Nanning, China

Full list of author information is available at the end of the article
}

(c) The Author(s). 2020 Open Access This article is licensed under a Creative Commons Attribution 4.0 International License, which permits use, sharing, adaptation, distribution and reproduction in any medium or format, as long as you give appropriate credit to the original author(s) and the source, provide a link to the Creative Commons licence, and indicate if changes were made. The images or other third party material in this article are included in the article's Creative Commons licence, unless indicated otherwise in a credit line to the material. If material is not included in the article's Creative Commons licence and your intended use is not permitted by statutory regulation or exceeds the permitted use, you will need to obtain permission directly from the copyright holder. To view a copy of this licence, visit http://creativecommons.org/licenses/by/4.0/ The Creative Commons Public Domain Dedication waiver (http://creativecommons.org/publicdomain/zero/1.0/) applies to the data made available in this article, unless otherwise stated in a credit line to the data. 


\section{Background}

Liver cancer is among the most common forms of cancer, and owing to its highly invasive nature it is the fourth leading cancer-related cause of death globally [1]. Hepatocellular carcinoma (HCC) accounts for approximately $80 \%$ of all liver cancer cases [2], and it can be difficult to reliably diagnose and treat in its early stages, as its detection is largely dependent upon imaging evaluations and biopsy. HCC treatments generally include hepatectomy, liver transplantation, radiofrequency ablation (RFA), and transcatheter arterial chemoembolization (TACE). As his disease is generally only detected when it is in an advanced stage, HCC patients generally have a poor overall prognosis [3, 4]. The identification of novel diagnostic and prognostic biomarkers associated with $\mathrm{HCC}$ is thus very important.

RNA binding proteins (RBPs) are a broad class of highly-conserved RNA-interacting proteins, of which roughly $60 \%$ are expressed in a tissue-specific manner [5]. Genome-wide screening analyses have detected over 1500 RBPs in the human genome. These proteins are capable of binding to diverse RNA types (including rRNAs, ncRNAs, snRNAs, miRNAs, mRNAs, tRNAs, and snoRNAs), and can serve as key post-transcriptional regulators of gene expression to maintain intracellular homeostasis [6, 7]. RBP dysregulation has been shown to be associated with oncogenesis in multiple studies [8]. For example, Lin2 8 is an oncogenic RBP that has been found to promote the metastatic progression of diverse human cancers [9]. The RBP Musashi1 (Msi1) has been shown to promote glioma progression when its normal interactions with miR-137 are disrupted [10]. PUM2 is an RBP that is overexpressed in breast cancer and to be negatively correlated with OS and a lack of tumor recurrence in these patients [11]. The RBP insulin-like growth factor 2 mRNA-binding protein 3 (IGF2BP3) has similarly been found to be overexpressed in mixed-lineage leukemia-rearranged (MLL rearranged) B-acute lymphoblastic leukemia (B-ALL) and to be associated with poorer outcomes and higher recurrence risks in these patients [12]. There is also specific evidence linking certain RBPs to liver cancer. For example, Sorbin and $\mathrm{SH} 3$ domain containing 2 (RBPSORBS2) expression is reduced in HCC patients and associated with a poor prognosis. This RBP is believed to function via regulating RORA expression to control liver cancer onset and metastasis [13]. RBM3 is an RBP capable of promoting HCC cell proliferation owing to its ability to regulate SCD-CircRNA2 production, with RBM3 overexpression being linked to reduced $\mathrm{OS}$ and decreased recurrencefree survival (RFS) in HCC patients [14]. While these findings are informative, few studies to date have systematically evaluated RBP expression patterns in liver cancer.
In the present study, we downloaded HCC patient gene expression and clinical data from The Cancer Genome Atlas (TCGA) database, after which we used these data to identify RBPs that were differentially expressed in $\mathrm{HCC}$ tumor tissues relative to healthy normal tissues. We further explored the functional roles of these RBPs through protein-protein interaction (PPI) network, gene ontology (GO) enrichment analyses, and Kyoto gene and genome encyclopedia (KEGG) pathway analyses. We also constructed a prognostic model based upon seven key hub RBPs, identifying them as potentially viable diagnostic and prognostic biomarkers of HCC.

\section{Methods}

Data collection

We downloaded level 3 mRNA expression and clinical data from $374 \mathrm{HCC}$ and 50 normal control samples from the TCGA - liver HCC dataset (TCGALIHC)(https://portal.gdc.cancer.gov/).

\section{Differentially expressed RBP identification}

Appropriate $\mathrm{R}$ packages were used to standardize data by excluding genes with an average count $<1$. Differentially expressed RBPs were then identified using $R$ (v3.6.0) with the following criteria: $|\log 2 \mathrm{FC}| \geq 1$ and FDR $<0.05$.

\section{Functional enrichment analyses}

In order to explore the functional roles of these differentially expressed RBPs, they were next separated into those that were upregulated and downregulated in HCC. The clusterProfiler R package [15] was then used to conduct GO and KEGG pathway enrichment [16] analyses on these two groups of RBPs, with $P<0.05$ and FDR $<$ 0.05 being used as significance thresholds.

\section{PPI network construction and analysis}

The STRING database (http://www.string-db.org/) [17] was used to assess interactions between proteins related to these differentially expressed RBPs, with Cytoscape v3.7.1 being used to construct a PPI network. The MCODE plugin was then used to identify key modules and hub genes within this network based on the following criteria: degree cutoff $=5$, node score cutoff $=0.2, \quad \mathrm{k}$-core $=5, \quad$ max.depth $=100 \quad$ truncation standard, and $P<0.05$ was the significance threshold.

\section{Evaluation of hub gene prognostic relevance}

Follow-up analyses incorporated all HCC patients surviving for at least 30 days. Hub RBPs associated with patient prognosis were identified through univariate Cox regression analyses, with patients being randomly separated into training and test cohorts. RBPs identified in these initial analyses were then assessed via a 
multivariate stepwise Cox regression approach to identify hub RBPs individually associated with HCC patient OS.

\section{Prognostic risk score model construction and analysis}

A prognostic risk score model was constructed using patients in the training cohort $(n=172)$ based upon multivariate stepwise Cox regression model coefficient $(\beta)$ values for selected hub RBPs. Risk scores for $n$ hub genes were computed as follows: risk score $=(\beta-\mathrm{mRNA} 1$ $*$ expression mRNA1 $)+(\beta$-mRNA2 * expression mRNA2 $)+(\beta-$ mRNA3 $* \quad$ expressionmRNA3 $)+(\beta-$ mRNA $n$ * expression mRNA $n$ ). The R survival and Survminer packages were used to select the optimal risk score cutoff values [18]. HCC patients were then separated into low- and high-risk groups based upon median risk score values. The OS of patients in these two risk groups was then compared using Kaplan-Meier survival curves and log-rank sum tests with the R survival package. The Survival ROC package was additionally utilized for time-related ROC analyses assessing the value of individual hub RBPs as predictors of patient OS. These analyses were then repeated in the test group of patients.

\section{Nomogram construction}

Nomograms have been used to predict outcomes in patients with a range of cancer types [19]. In order to construct a nomogram in the present study, the multivariate Cox analysis results pertaining to hub RBPs were used to construct line diagrams. Total nomogram scores were then used to predict 1-, 3-, and 5-year OS in HCC patients in both the training and test cohorts.

\section{Assessment of the correlation between risk scores and clinical characteristics}

Logistic regression analyses of the entire TCGA-LIHC cohort were used to analyze the relationship between risk scores and HCC clinical characteristics. These clinical parameters included age, fender, AFP, Hepatitis B or $\mathrm{C}$ status, and alcohol consumption. $P<0.05$ was the significance threshold.

\section{Assessment of the independent prognostic relevance of risk scores}

The independent prognostic relevance of hub RBP risk scores, age, sex, tumor grade, tumor stage, and TNM stage was analyzed through univariate and multivariate Cox regression analysis. TCGA entries with incomplete data were omitted from these analyses. $\mathrm{P}<0.05$ was the significance threshold.

\section{Prognostic RBP validation}

To analyze the prognostic relevance of identified hub RBPs in HCC patients, we utilized Kaplan-Meier curves.
The survival $\mathrm{R}$ package was used to compute $P$-values corresponding to these curves via the log-rank test, with $\mathrm{P}<0.05$ as the significance threshold.

\section{Hub RBP-PCG co-expression network construction}

A co-expression network of hub RBPs and proteincoding genes (PCGs) was additionally constructed in order to further explore the potential mechanisms whereby hub RBPs influence tumor development. Pearson correlation coefficients between RBP and PCG expression levels were calculated, and when these coefficients were $>0.5$ or $<-0.5$ with a $p$-value $<0.01$, this was indicative of a significant correlation. An RBPPCG co-expression network was constructed using these values, and GO and KEGG enrichment analyses of PCGs were performed.

\section{Results}

\section{Differentially expressed RBP identification}

In total, we evaluated the expression of 1542 different RBPs in $374 \mathrm{HCC}$ tumors and 50 normal tissue samples [6]. Of these, we identified 81 differentially expressed RBPs, including 54 and 27 that were upregulated and downregulated, respectively $(|\log 2 \mathrm{FC}|>1.0$ and $P<0.05)$ (Fig. 1).

\section{Functional enrichment analyses}

GO and KEGG analyses were next used to assess the potential functional roles of up- and down-regulated RBPs in HCC patients. GO analyses revealed upregulated RBPs to be enriched for roles in mRNA metabolic processes, RNA catabolic processes, DNA methylation or demethylation, DNA modification, and mRNA catabolic processes (Fig. 2a). In contrast, downregulated RBPs were enriched for roles in RNA catabolic processes, intracellular mRNA localization, translational regulation, 3' - UTR - mediated mRNA destabilization, and RNA phosphodiester bond hydrolysis (Fig. 2b). With respect to molecular functions, upregulated RBPs were enriched in mRNA 3' - UTR binding, catalytic activity, acting on RNA, translation regulator activity, poly $(\mathrm{U})$ RNA binding, and poly-pyrimidine tract binding (Fig. 2a), whereas downregulated RBPs were enriched in mRNA 3' - UTR $\mathrm{AU}$ - rich region binding, $\mathrm{AU}$ - rich element binding, mRNA 3'-UTR binding, ribonuclease activity and double-stranded RNA binding (Fig. 2b). Upregulated RBPs were additionally enriched in the cytoplasmic ribonucleoprotein granule, ribonucleoprotein granule, cytoplasmic stress granule, telomerase holoenzyme complex, and cytosolic large ribosomal subunit compartments (Fig. 2a), while downregulated RBPs were primarily enriched in mRNA cap-binding complex, RNA capbinding complex, endolysosome membrane, and apical dendrite compartments (Fig. 2b). Upregulated RBPs 


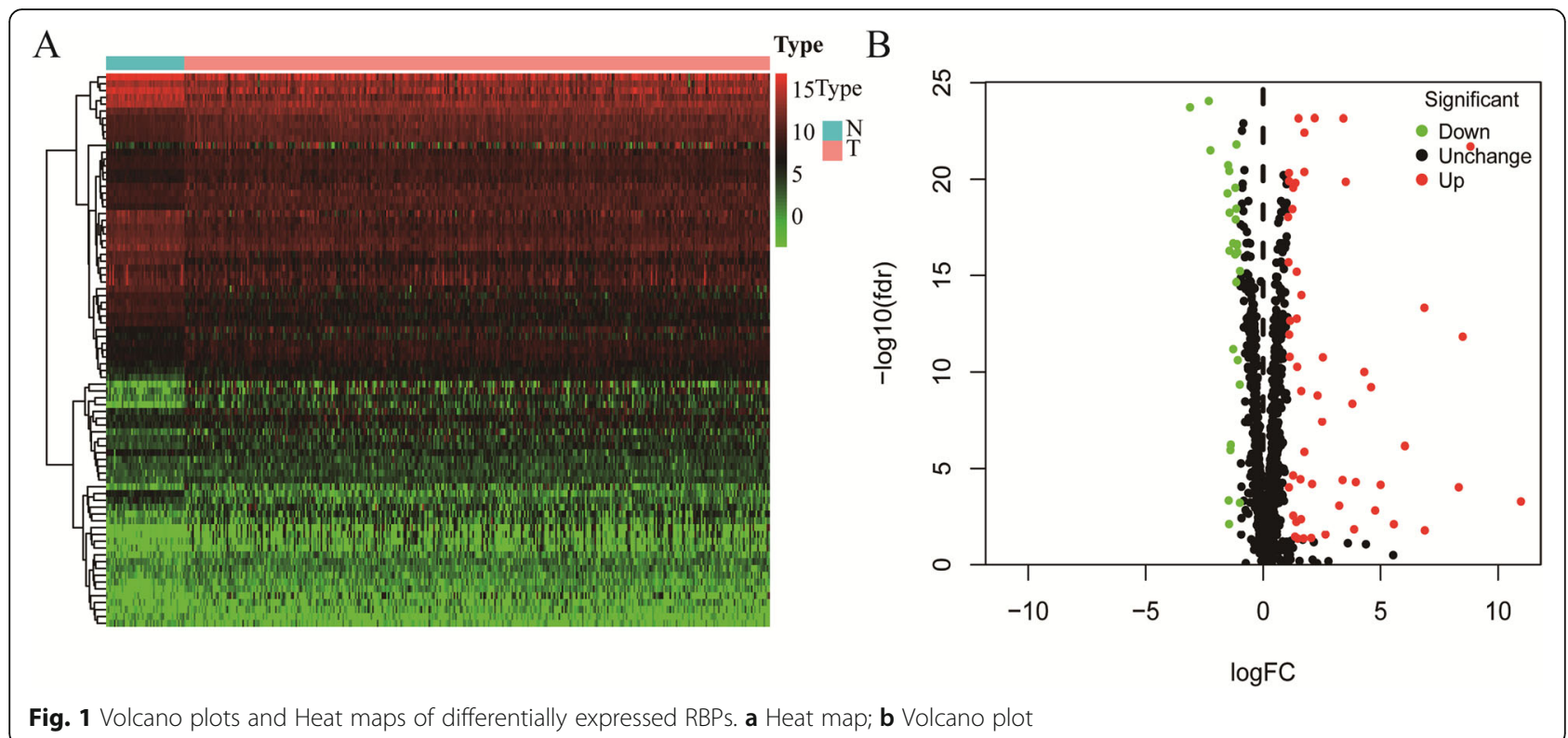

were additionally enriched in the mRNA surveillance pathway, microRNAs in cancer, RNA transport, RNA degradation, DNA replication, and cysteine and methionine metabolism KEGG pathways (Table 1), whereas downregulated RBPs were enriched in the influenza A, mRNA surveillance, and Hepatitis C pathways (Table 1).

\section{PPI network construction and analysis}

We next utilized Cytoscape (3.7.1) to construct a PPI network based on the STRING database. The resultant network incorporated 66 nodes and 127 edges (Fig. 3a). Key co-expressed modules within this network were then identified using the MCODE plugin (Fig. 3b). Functional enrichment analyses revealed that hub RBPs within this network were enriched in mRNA catabolic processes, RNA catabolic processes, mRNA surveillance pathways, and ribosome pathways.

\section{Identification of hub RBPs associated with HCC patient prognosis}

We next randomly separated 343 total HCC patients in the TCGA-LIHC dataset that had survived for a minimum of 30 days into a training cohort $(n=172)$ and a test cohort $(n=171)$. These two patient cohorts were
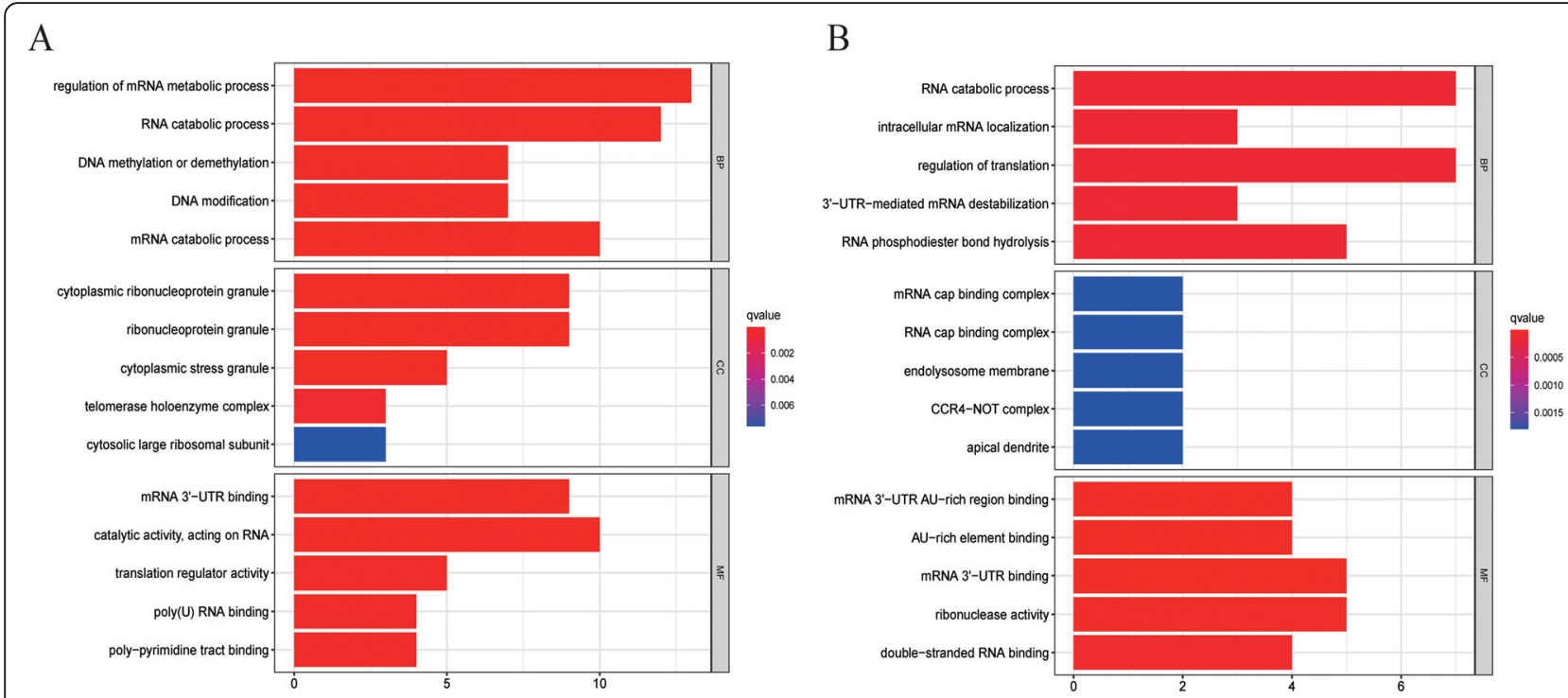

Fig. 2 The top 5 significantly enriched GO annotations associated with differentially expressed RBPs. a Up-regulated RBPs; b down-regulated RBPs. Where CC stands for cellular component, BP for the biological process, and MF for molecular function 
Table 1 Analysis of KEGG pathway of aberrantly expressed RBPs

\begin{tabular}{lll}
\hline Term & Count & $\boldsymbol{p}$-value \\
\hline Up-regulated RBPs & & \\
mRNA surveillance pathway & 5 & $1.71 \mathrm{E}-06$ \\
MicroRNAs in cancer & 5 & 0.00061399 \\
RNA transport & 4 & 0.00072374 \\
RNA degradation & 3 & 0.000789978 \\
DNA replication & 2 & 0.00317763 \\
Cysteine and methionine metabolism & 2 & 0.005824133 \\
Down-regulated RBPs & & \\
Influenza A & 4 & 0.000219498 \\
mRNA surveillance pathway & 3 & 0.000578381 \\
Hepatitis C & 3 & 0.002696851 \\
\hline
\end{tabular}

A
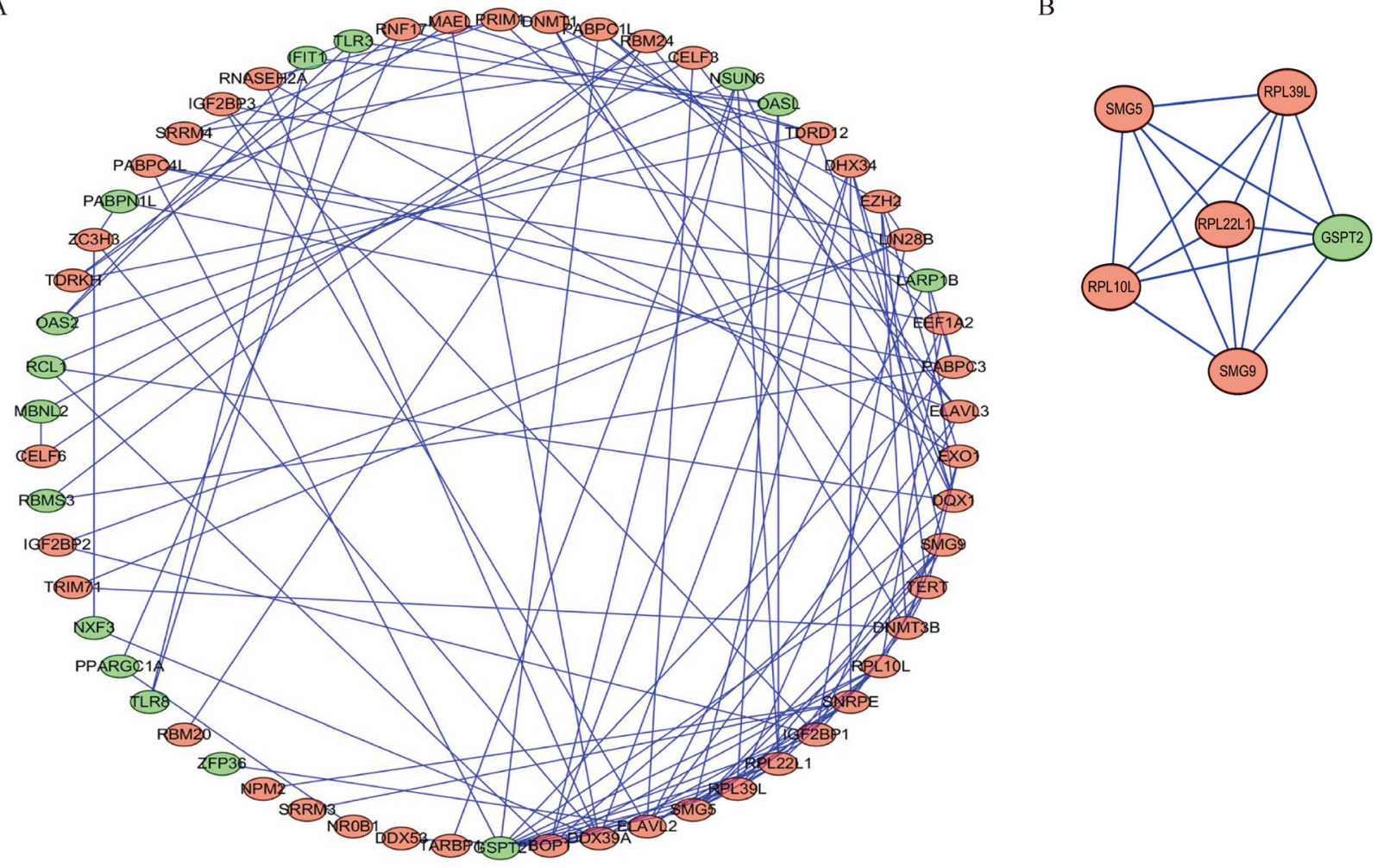

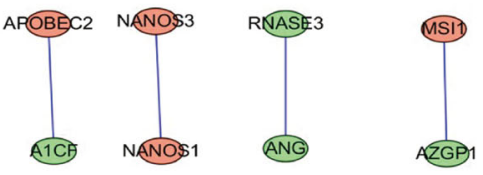

Fig. 3 Analysis of modules and network of protein-protein interaction. a The network of protein-protein interaction of differentially expressed RBPs; b A critical module from the network of PPI. Red circles: > 2-fold up-regulation Green circles: > 2-fold down-regulation 
A

$\begin{array}{lrr}\text { pvalue } & \begin{array}{r}\text { Hazard ratio } \\ \text { IGF2BP3 }\end{array} \\ \text { DNMT1 } & 0.032 & 1.076(1.006-1.151) \\ \text { IFIT1 } & 0.008 & 1.304(1.059-1.606) \\ \text { OASL } & 0.029 & 0.838(0.735-0.956) \\ \text { RPL10L } & 0.010 & 1.106(1.024-1.194) \\ \text { EZH2 } & <0.001 & 1.564(1.279-1.911) \\ \text { SMG5 } & <0.001 & 1.592(1.216-2.085) \\ \text { BOP1 } & 0.031 & 1.228(1.019-1.480) \\ \text { RCL1 } & <0.001 & 0.719(0.609-0.849) \\ \text { PRIM1 } & 0.022 & 1.247(1.033-1.505) \\ \text { RNASEH2A } & 0.014 & 1.266(1.048-1.530) \\ \text { LIN28B } & 0.002 & 1.084(1.031-1.140) \\ \text { DHX34 } & 0.001 & 1.651(1.213-2.248) \\ \text { EXO1 } & <0.001 & 1.293(1.114-1.500) \\ \text { RNF17 } & 0.007 & 1.101(1.026-1.182) \\ \text { ANG } & <0.001 & 0.838(0.760-0.924) \\ \text { AZGP1 } & 0.006 & 0.900(0.836-0.970) \\ \text { PPARGC1A } & <0.001 & 0.870(0.811-0.932) \\ \text { LARP1B } & 0.026 & 0.770(0.611-0.969) \\ \text { CELF6 } & 0.020 & 0.821(0.695-0.969) \\ \text { RBMS3 } & 0.019 & 0.836(0.720-0.971) \\ \text { NR0B1 } & <0.001 & 1.162(1.097-1.230)\end{array}$

B

$\begin{array}{lrr} & \text { pvalue } & \text { Hazard ratio } \\ & & \\ \text { SMG5 } & 0.002 & 2.094(1.326-3.308) \\ & & \\ \text { BOP1 } & 0.011 & 1.556(1.105-2.192) \\ \text { LIN28B } & 0.113 & 1.063(0.986-1.146) \\ \text { RNF17 } & 0.131 & 1.098(0.972-1.240) \\ & & \\ \text { ANG } & 0.002 & 0.757(0.635-0.904) \\ & & \\ \text { LARP1B } & 0.013 & 1.823(1.136-2.926) \\ \text { NR0B1 } & 0.145 & 1.076(0.975-1.187)\end{array}$

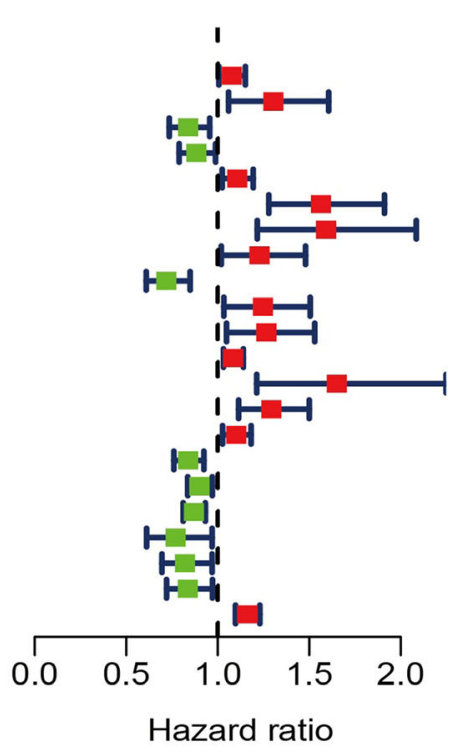

I

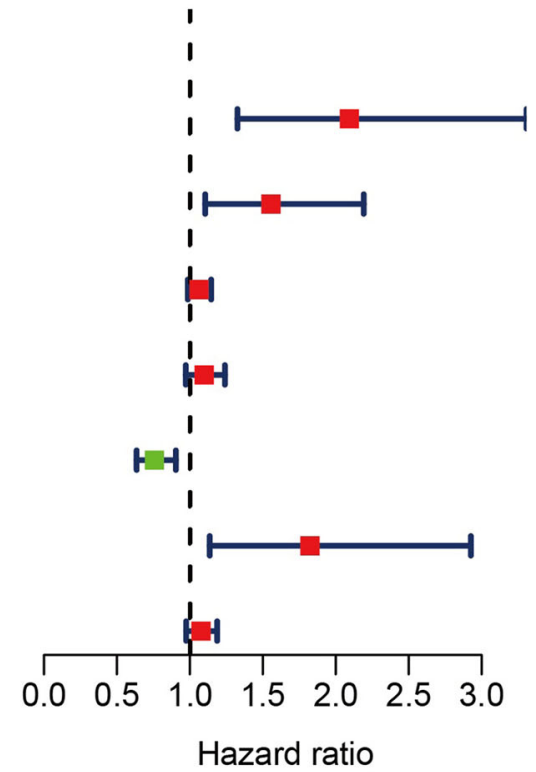

Fig. 4 Forest plot for univariate and multivariate Cox regression analyses of HCC patients. a Univariate Cox regression analysis for the hub RBPs identification in the TCGA patient cohort; $\mathbf{b}$ Multivariate Cox regression analysis for the identification of hub RBPs related to patient prognosis in the training set $(n=172)$

survival and time-dependent ROC analyses. This analysis confirmed that the OS of HCC patients in the high-risk group was significantly reduced relative to that of patients in the low-risk group (Fig. 5a), with an area under the ROC curve value of 0.801 for this seven RBP risk score model (Fig. 5b), consistent with its moderate diagnostic performance. In Fig. 5c, mRNA expression levels, survival status, and risk score values for patients in the low- and high-risk groups are shown. We then utilized this same risk score formula to analyze patients in the test cohort $(n=171)$ (Fig. 6a-c). Consistent with the above results, HCC patients in the low-risk group exhibited an OS that was significantly longer than that of patients in the high-risk group, with an area under the ROC curve of 0.676 . This thus indicates that our prognostic model was able to successfully predict HCC patient survival outcomes.

\section{Construction of a hub RBP-based prognostic nomogram}

A nomogram incorporating the results of the above multivariate Cox regression analysis pertaining to the seven hub RBPs was next constructed and used to predict 1-, 3-, and 5-year HCC patient OS (Fig. 7) in our training dataset. This analysis revealed that patient 1-, 
A
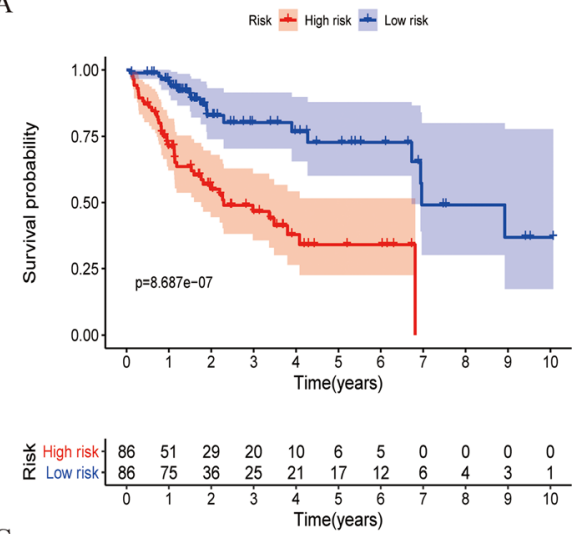

$\mathrm{C}$
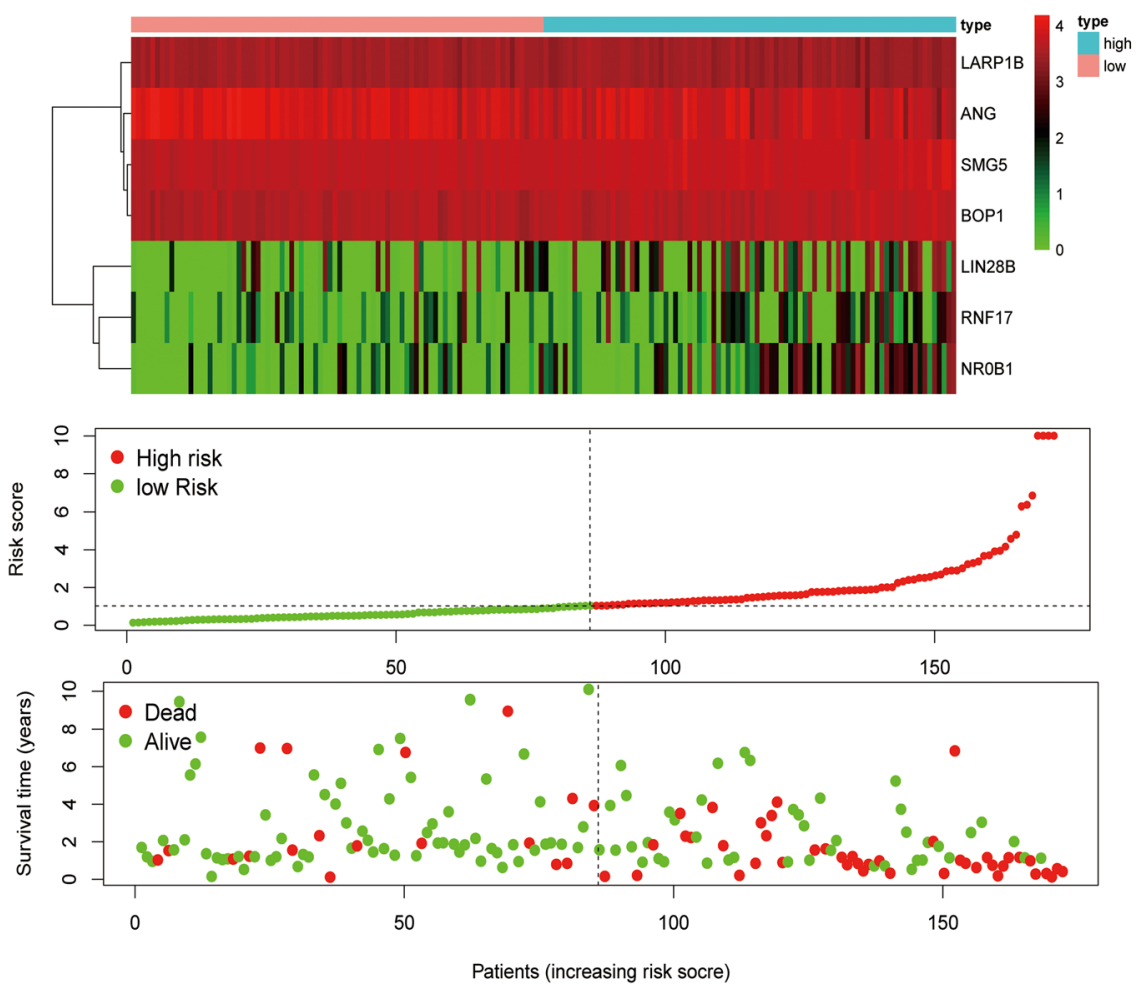

Fig. 5 Risk score analysis of a seven hub RBP-based prognostic model in the training set $(n=172)$. a Survival curves for high- and low-risk patient groups; b ROC curves used to predict OS on the basis of risk score; c Expression survival status, distribution of risk score, and heat map

3-, and 5-year OS declined as risk scores increased, consistent with our above results, confirming the prognostic value of this risk nomogram.

\section{The relationship between risk scores and clinical} parameters

Logistic regression analyses were used to assess the relationship between risk scores and HCC clinical characteristics, revealing that high risk scores were associated with low histological grade $(\mathrm{G} 3-4$ vs $\mathrm{G} 1-2, \mathrm{OR}=2.060)$ and high AFP levels $(>20 \mathrm{ng} / \mathrm{mL}$ vs $<=20 \mathrm{ng} / \mathrm{mL}, \mathrm{OR}=$ 1.986) $(P<0.05)$. In contrast, these scores were unrelated

B

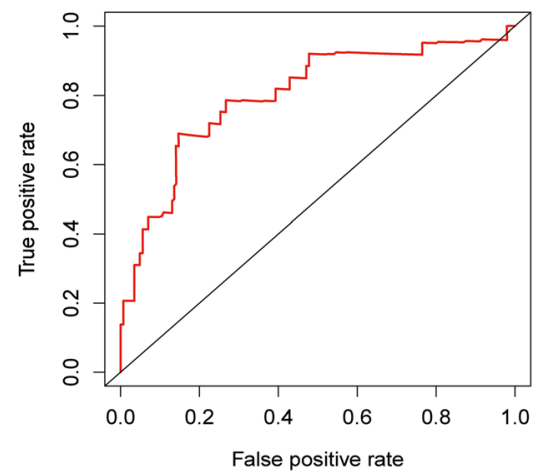


A
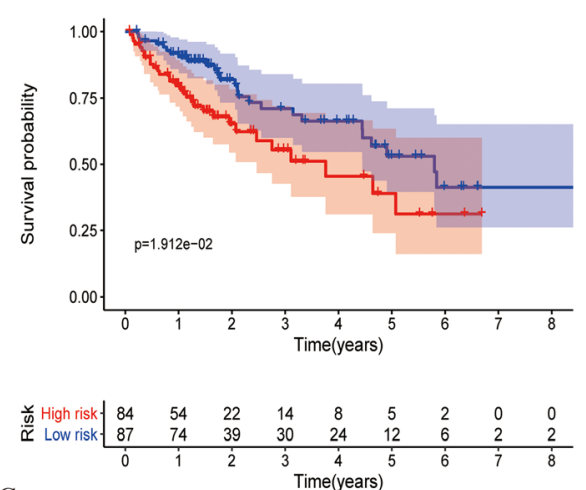

C
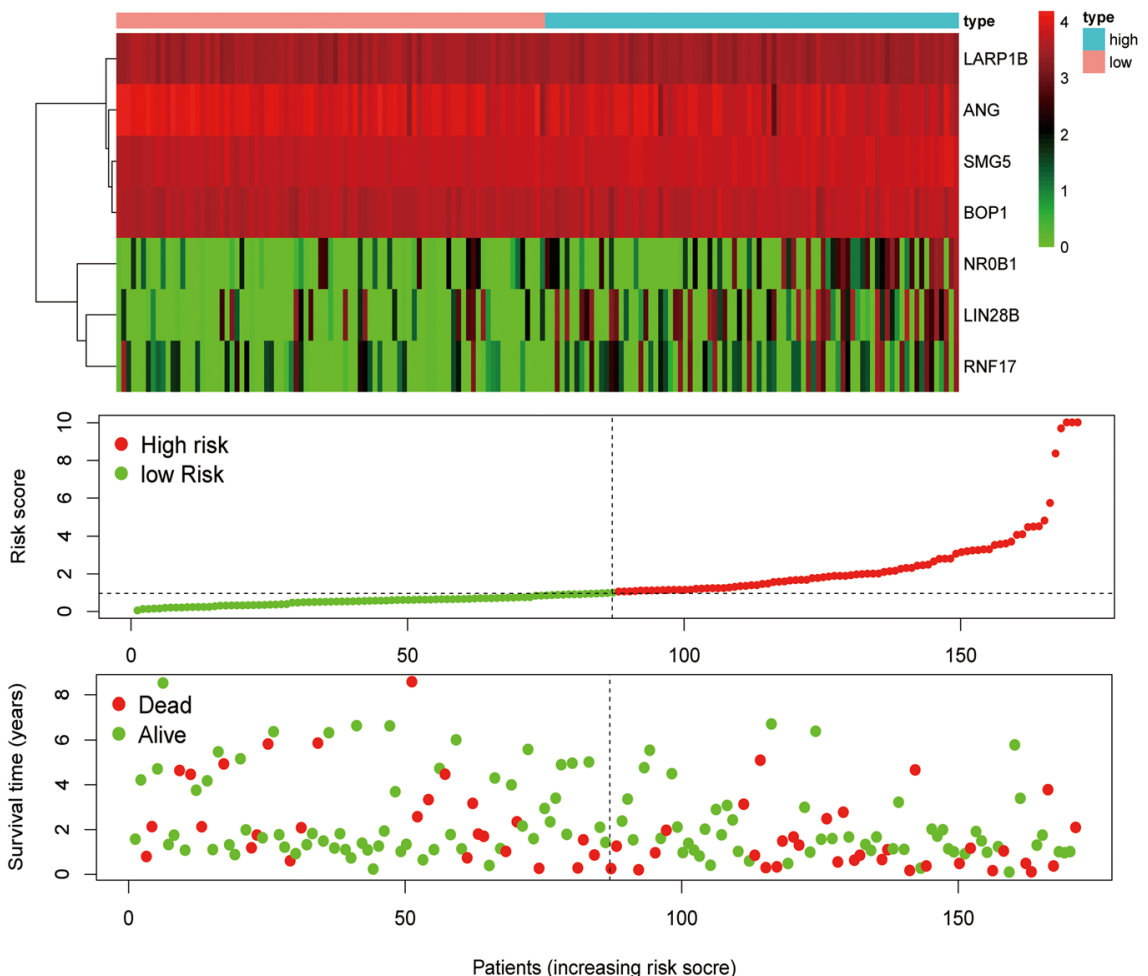

Fig. 6 Analysis of risk score of a seven hub RBP-based prognostic model in the testing set $(n=171)$. a Survival curves for high-and low-risk patient groups; $\mathbf{b}$ ROC curves used to predict OS on the basis of risk score; c Expression survival status, distribution of risk score, and heat map

was an independent predictor of HCC patient OS, with a hazard ratio (HR) of 1.160 and a $95 \%$ confidence interval of 1.095-1.229 ( $P=4.305 \mathrm{E}-07)$ (Fig. 8b).

\section{Validation of hub RBP prognostic value}

Lastly, the relationship between identified hub RBPs and HCC patient OS was evaluated using the KaplanMeier plotter database. This analysis confirmed that 4/ 7 hub RBPs (ANG, LIN28B, SMG5, and NR0B1) were significantly associated with HCC patient OS, with respective $P$-values of $0.017,0.013,0.002$, and 0.003 (Fig. 9a-d).

B

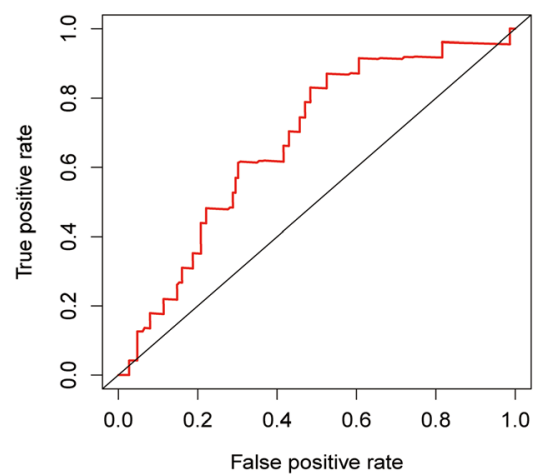

\section{it:}

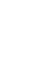




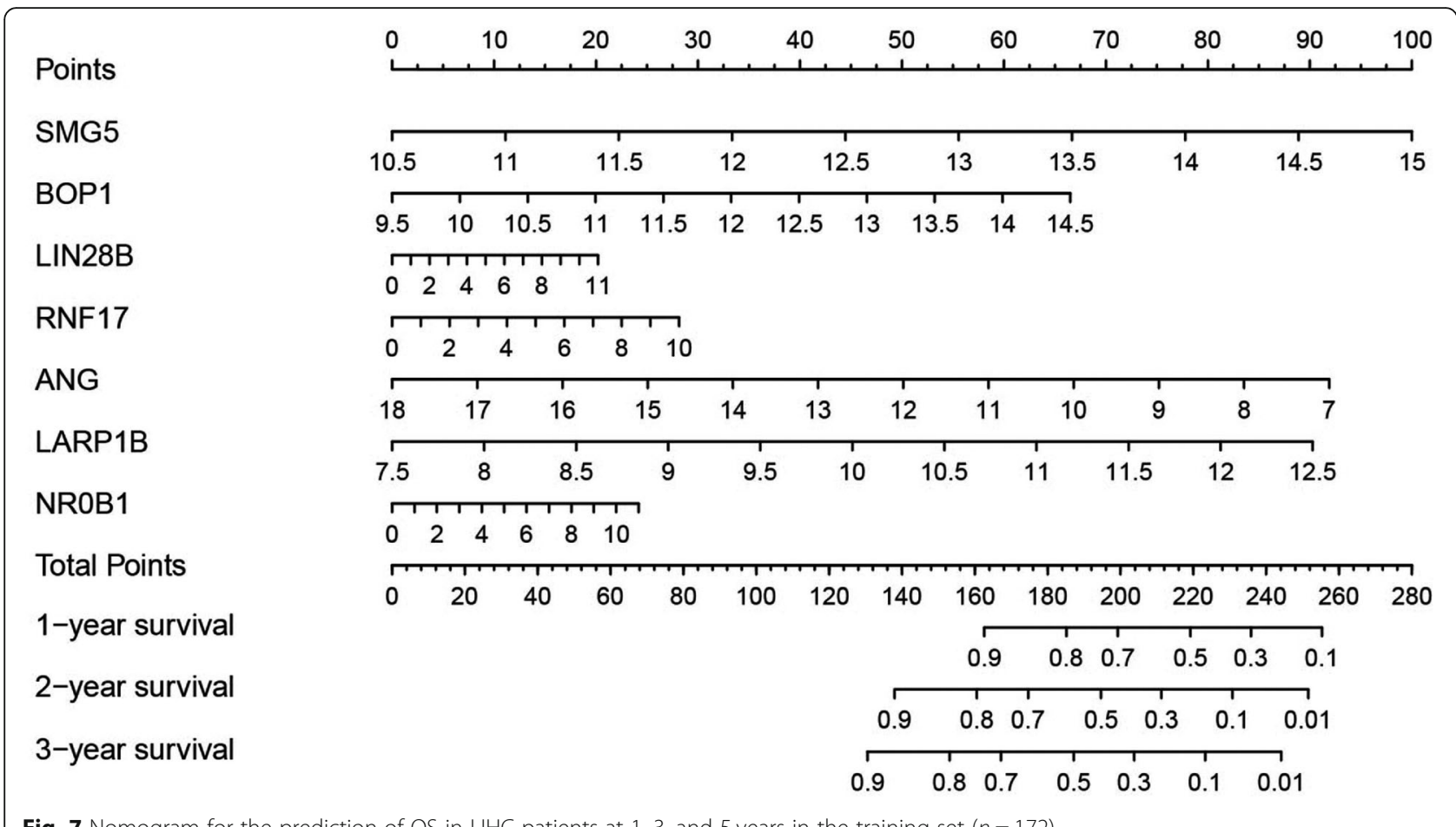

Fig. 7 Nomogram for the prediction of OS in LIHC patients at 1, 3, and 5 years in the training set $(n=172)$

\section{Discussion}

While available treatments for HCC have improved significantly in recent years [20], it remains a condition associated with high rates of morbidity and mortality [21]. As such, it is essential that novel diagnostic and prognostic biomarkers of HCC be identified in order to improve patient outcomes.

RBP dysregulation has been shown to be a hallmark of many tumor types [8]. In gliomas [10], breast cancer [11], and B-ALL [12], RBPs have been found to be directly related to tumor development and patient prognosis. In the present study, we identified 81 RBPs that were differentially expressed in HCC tissues relative to healthy control tissues in the TCGA-LIHC dataset. We analyzed the biological roles of these RBPs through functional enrichment analyses and by constructing a PPI network, after which we employed Cox regression analyses, survival analyses, and time-dependent ROC analyses of key hub RBPs within this network to construct a prognostic risk model. This model was capable of predicting HCC patient OS based upon the intratumoral expression of seven key RBPs. As such, our results

Table 2 The relationship between risk scores and HCC clinical characteristics

\begin{tabular}{llll}
\hline parameter & count $(\mathbf{N})$ & Odds ratio in riskScore & p-Value \\
\hline age $(>60$ vs $<=60)$ & 343 & $1.279(0.837-1.958)$ & 0.256 \\
Sex (male vs female) & 343 & $1.164(0.740-1.836)$ & 0.511 \\
AFP(> 20 ng/mLvs<=20 ng/mL) & 260 & $1.986(1.215-3.270)$ & $\mathbf{0 . 0 0 6}$ \\
Hepatitis B or C (Yes vs No) & 315 & $0.670(0.428-1.046)$ & 0.079 \\
Alcohol consumption (Yes vs No) & 315 & $1.161(0.731-1.846)$ & 0.528 \\
Cirrhosis status (Yes vs No) & 199 & $0.612(0.334-1.110)$ & 0.108 \\
Vascular invasion (Yes vs No) & 289 & $1.042(0.642-1.692)$ & 0.868 \\
Grade (G3-4 vs G1-2) & 338 & $2.060(1.316-3.249)$ & $\mathbf{0 . 0 0 2}$ \\
Stage (Stage III-IV vs Stage I-II) & 321 & $1.649(0.997-2.751)$ & 0.053 \\
T (T3-4 vs T1-2) & 340 & $1.541(0.946-2.527)$ & 0.084 \\
N (N1 vs N0) & 242 & $2.017(0.191-43.740)$ & 0.569 \\
M (M1 vs M0) & 248 & $2.016(0.191-43.723)$ & 0.569 \\
\hline
\end{tabular}


A

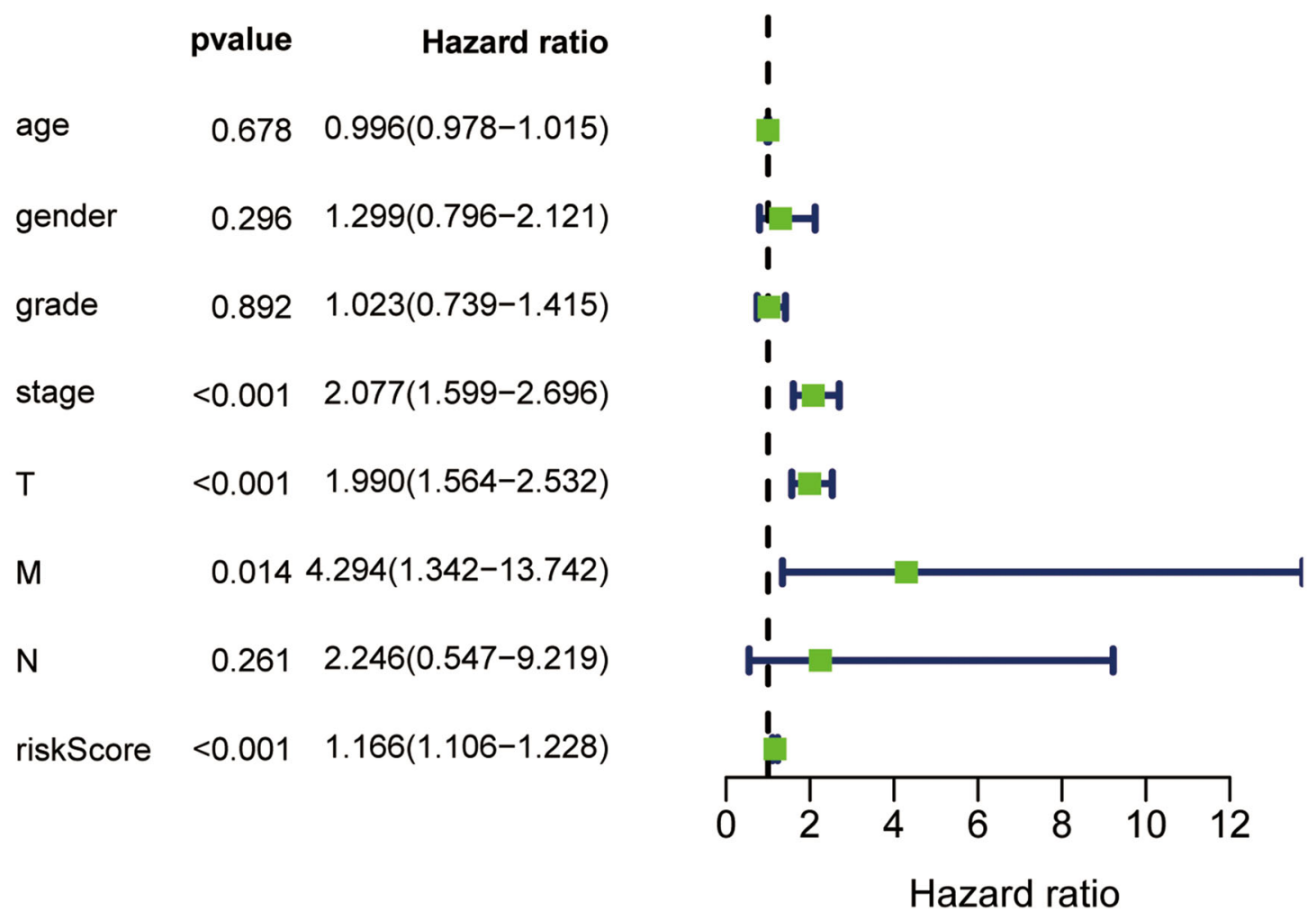

$\mathrm{B}$

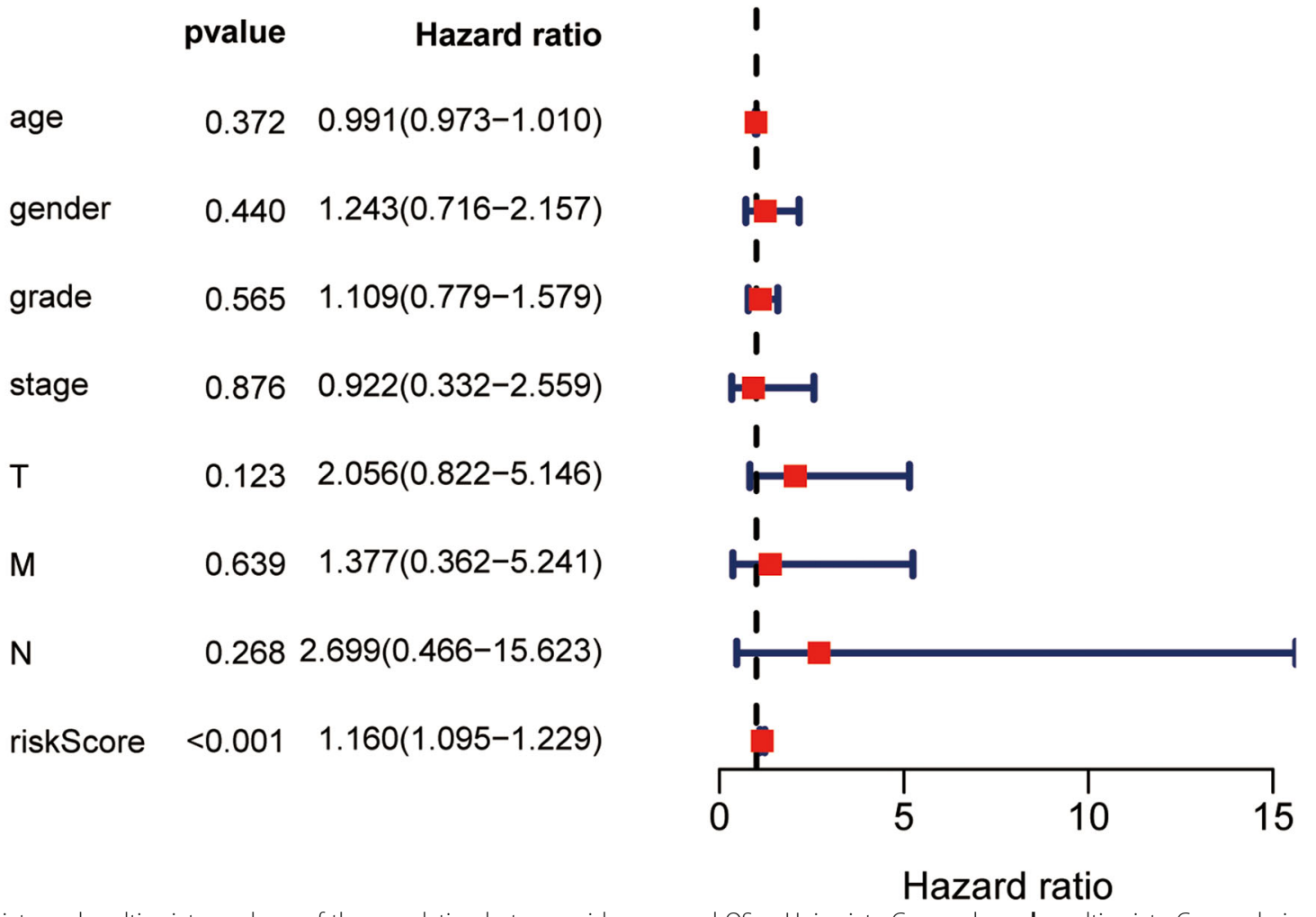




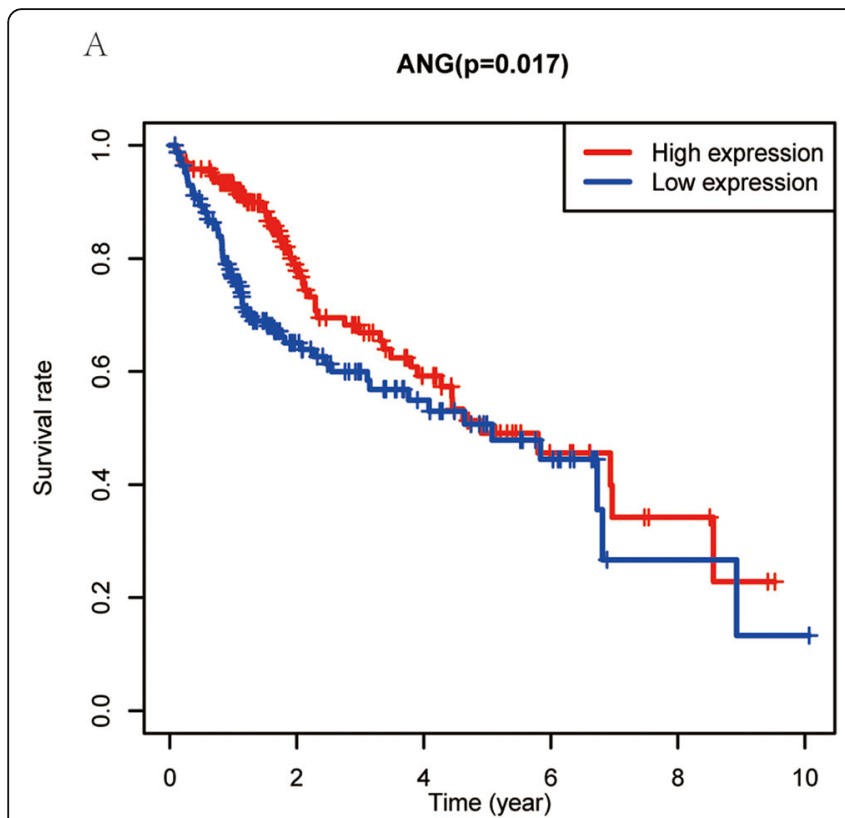

C

$\operatorname{NR0B1}(p=0.003)$

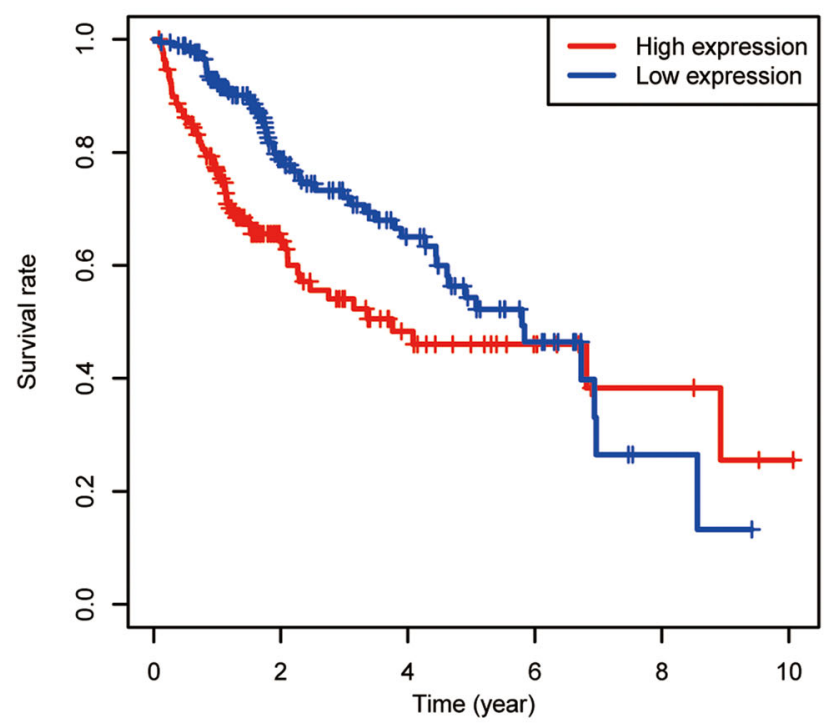

B

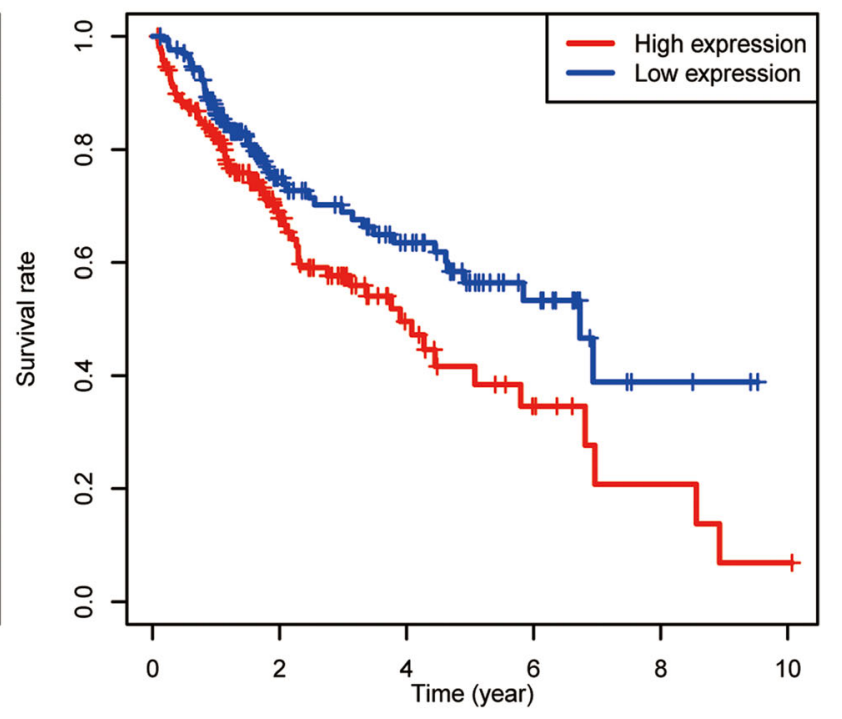

D

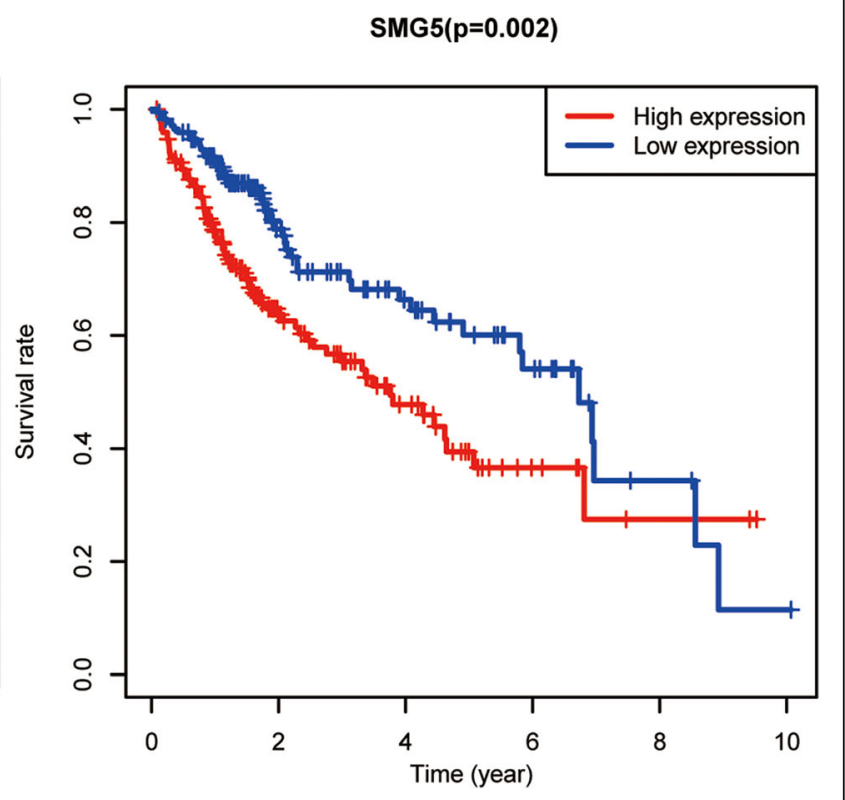

Fig. 9 Validation of the hub RBPs prognostic value in HCC patients in the TCGA cohort

highlight these RBPs as novel prognostic biomarkers of $\mathrm{HCC}$, and additionally identify these genes as potential diagnostic or therapeutic targets. These differentially expressed RBPs were found to be functionally enriched in pathways relating to the regulation of mRNA metabolism, RNA catabolism, DNA methylation or demethylation, DNA modification, translation regulation, mRNA3'-UTR binding, ribonuclease activity, ribonucleoprotein granule, telomerase holoenzyme complex, and dsRNA binding. It has been reported that human ribosomal protein S3 (RPS3) regulates the expression of silent information regulator 1 (SIRT1) after transcription to promote liver cancer [22]. IGF2 mRNA-binding proteins (IGF2BPs) can specifically bind to the lncRNA HULC (Highly Up-regulated in Liver Cancer) HULC, thereby controlling its expression [23]. Polypyrimidine tract-binding protein 1 (PTBP1) is highly expressed in hepatocellular carcinoma and promotes the translation of cyclin D3 (CCND3) via interacting with the $5^{\prime}$-untranslated region (5'-UTR) of its mRNA, thereby playing a role in the development of hepatocellular carcinoma [24].RBPs are capable of specifically binding to 
Table 3 The top 10 PCGs correlated with SMG5 expression

\begin{tabular}{lll}
\hline Correlated PCG & Spearman's Correlation & $\boldsymbol{p}$-value \\
\hline ISG20L2 & 0.8 & $9.48 \mathrm{E}-96$ \\
DENND4B & 0.8 & $8.02 \mathrm{E}-96$ \\
UBQLN4 & 0.801 & $4.57 \mathrm{E}-96$ \\
PI4KB & 0.805 & $1.19 \mathrm{E}-97$ \\
SLC39A1 & 0.808 & $5.05 \mathrm{E}-99$ \\
TTC36 & -0.563 & $7.86 \mathrm{E}-37$ \\
CLEC4M & -0.534 & $1.07 \mathrm{E}-32$ \\
FCN2 & -0.514 & $5.75 \mathrm{E}-30$ \\
MFSD2A & -0.511 & $1.53 \mathrm{E}-29$ \\
MT1X & -0.508 & $3.48 \mathrm{E}-29$ \\
\hline
\end{tabular}

conserved 3'-UTR sequences in target mRNAs, thereby modulating their stability and subsequent translation $[25,26]$. Appropriate regulation of DNA modification is essential to ensure that chromosomes replicate correctly, and that genes are expressed or silenced in a contextappropriate manner [27]. Promoter or gene body hypermethylation can lead to the inactivation of key tumor suppressor genes, and methylation-based epigenetic silencing of specific genes is a hallmark of many forms of cancer [28]. There are also many studies that show that telomerase plays an important role in the development of liver cirrhosis and liver cancer [29]. Our KEGG pathway analyses further suggested that these dysregulated RBPs may be linked to HCC onset and progression owing to their ability to influence mRNA monitoring pathway, microRNA, RNA transport, RNA degradation, and DNA replication pathway. For example, microRNAs have been shown to play an important role in posttranscriptional regulation of gene expression. Indeed, microRNA dysregulation is thought to be associated with tumor suppressor gene inactivation and oncogene activation in liver cancer [30]. The mRNA monitoring pathway is essential for maintaining homeostasis such that when this regulation is disrupted it can facilitate tumor pathogenesis [31]. As such, these mechansims may explain how differentially expressed RBPs are associated with the development of liver cancer.

Through Cox regression analyses, we detected seven key RBPs that were associated with HCC patient prognosis, including SMG5, BOP1, LIN28B, RNF17, ANG, and LARP1B. These seven hub RBPs exhibit telomerase RNA binding, ribonucleoprotein complex binding, DNA binding, ribonuclease, DNA-binding transcription factor, and RNA polymerase II-specific functions [32-34]. They are additionally involved in the regulation of telomere maintenance, the cell cycle, RNA 3 '-end processing, cell migration, and in the negative regulation of transcription [33, 35-38]. These genes are closely linked to tumor development. In prior studies, BOP1 has been shown to promote liver cancer development via driving epithelial to mesenchymal transition [39]. Lin28b is a miR-125a target gene that, when downregulated, can inhibit liver cancer cell proliferation [40], NR0B1 (also called DAX-1) can inhibit the proliferation of liver cancer cells by suppressing the transcriptional activity of $\beta$-catenin [41]. In HCC patients, plasma samples contain high levels of angiopoietin-1 (Ang-1), and patients with low angiopoietin-2 (Ang-2) levels exhibit better OS [42]. We then employed a multivariate stepwise Cox regression analysis to establish a risk model incorporating these seven hub RBPs that can be used to predict HCC patient prognosis. Time-dependent ROC curve analyses revealed that these seven genes offered good diagnostic ability, and that our risk model could be readily used to identify HCC patients with a poor prognosis. However, few studies to date have explored the molecular mechanisms whereby these hub RBPs influence HCC pathogenesis, and as such, further research is essential. We additionally constructed a nomogram capable of predicting the 1-, 3-, and 5year HCC patient OS. In addition, we utilized Kaplan-Meier curves to assess the prognostic value of these seven hub RBPs, with four of them being found to be associated with patient outcomes. We also constructed a co-expression network of SMG5 and correlated PCGs in order to discover its potential downstream target genes and to explore the possible regulation of RBPs involved in the development of liver cancer. We found that PCGs associated with SMG5 were related to tumorigenesis. Closely-related genes such as UBQLN4 are upregulated in aggressive tumors and promote non-homologous end binding (NHEJ) during DSB repair, resulting in DNA mismatches [43]. HCC patients exhibiting CLEC4M overexpression have a better OS, and CLEC4M overexpression inhibits the proliferation of liver cancer cells and promotes their apoptotic death [44]. KEGG pathway enrichment analyses revealed that these PCGs were enriched in the mTOR, AMPK, and VEGF signaling pathways, all of which are closely linked to cancer development and progression [4547]. These pathways may thus be one mechanism whereby these RBPs participate in the occurrence and development of liver cancer and other malignancies. As such, these differentially expressed hub RBPs offer clear value in the assessment of HCC patients and may represent viable therapeutic targets. Despite the lack of effective adjuvant therapy for liver cancer, the application of targeted drugs provides a promising opportunity for imporiving the prognosis of those affected by this disease [48]. 


\section{Conclusions}

In summary, in the present study we developed a predictive model of HCC patient survival based upon the expression of seven key RBPs within tumor tissues. While this model exhibited significant prognostic value, this study is limited by the fact that it is solely based upon data within the TCGA database and lacks any external validation. In addition, we have not explored the functional roles of these RBPs in the context of HCC, and as such, future in vitro and in vivo analyses will be necessary to confirm and expand upon our findings. In addition, candidate RBPs may provide insight into the regulation of $\mathrm{HCC}$ while offering value as prognostic biomarkers.

\begin{abstract}
Abbreviations
HCC: hepatocellular carcinoma; RBPs: RNA-binding proteins; TCGA-LIHC: the Cancer Genome Atlas - liver HCC; OS: overall survival; PCGs: protein-coding genes; RFA: recurrence-free survival; TACE: transcatheter arterial chemoembolization; RFS: recurrence-free survival; TCGA: The Cancer Genome Atlas; PPI: protein-protein interaction; GO: gene ontology; KEGG: Kyoto gene and genome encyclopedia
\end{abstract}

\section{Acknowledgements}

The authors thank you for sharing the data in the Cancer Genome Atlas (TCGA) database.

\section{Authors' contributions}

MW conceived the study and performed the bioinformatics analyses. MW and $\mathrm{ZC}$ downloaded and organized the clinical and gene expression data. MW, ZC and ZH performed the statistical analyses. MW and SH wrote the manuscript. $\mathrm{KL}, C C, G W$ and $Y Z$ critically revised the article for essential intellectual content and administrative support. All authors read and approved the final.

\section{Funding}

This work was funded by Guangxi colleges and universities young and middle-aged teachers basic ability improvement project, Grant/Award Number: 2018KY0126; The central government guides local science and technology development projects (local professional technology innovation platforms), Grant/Award Number: GUIKE ZY1949017.

The funding agency did not have any role in design of the study, data collection, analysis, interpretation of the results and writing of the manuscript.

\section{Availability of data and materials}

The datasets analysed during the current study are available in the The Cancer Genome Atlas database (https://portal.gdc.cancer.gov/).

\section{Ethics approval and consent to participate}

Not applicable.

\section{Consent for publication}

Not applicable.

\section{Competing interests}

The authors declare that there are no conflicts of interest.

\section{Author details}

'Department of Hepatobiliary Surgery, Guangxi Medical University Cancer Hospital, Nanning, China. ${ }^{2}$ Department of Chinese Medicine, Guangxi Medical University Cancer Hospital, Nanning, China. ${ }^{3}$ Department of Experimental Research, Guangxi Medical University Cancer Hospital, Nanning, China.
Received: 2 July 2020 Accepted: 10 November 2020

Published online: 23 November 2020

\section{References}

1. Bray F, Ferlay J, Soerjomataram I, Siegel RL, Torre LA, Jemal A. Global cancer statistics 2018: GLOBOCAN estimates of incidence and mortality worldwide for 36 cancers in 185 countries. CA Cancer J Clin. 2018;68(6):394-424.

2. El-Serag HB, Rudolph KL. Hepatocellular carcinoma: epidemiology and molecular carcinogenesis. Gastroenterology. 2007;132(7):2557-76.

3. Bruix J, Reig M, Sherman M. Evidence-based diagnosis, staging, and treatment of patients with hepatocellular carcinoma. Gastroenterology. 2016;150(4):835-53.

4. Mak LY, Cruz-Ramón V, Chinchilla-López P, Torres HA, LoConte NK, Rice JP, et al. Global epidemiology, prevention, and Management of Hepatocellular Carcinoma. Am Soc Clin Oncol Educ Book. 2018;38:262-79.

5. Neelamraju Y, Hashemikhabir S, Janga SC. The human RBPome: from genes and proteins to human disease. J Proteomics. 2015;127(Pt A):61-70.

6. Gerstberger $\mathrm{S}$, Hafner M, Tuschl T. A census of human RNA-binding proteins. Nat Rev Genet. 2014;15(12):829-45.

7. Dreyfuss G, Kim VN, Kataoka N. Messenger-RNA-binding proteins and the messages they carry. Nat Rev Mol Cell Biol. 2002;3(3):195-205.

8. Pereira B, Billaud M, Almeida R. RNA-binding proteins in Cancer: old players and new actors. Trends Cancer. 2017;3(7):506-28.

9. Jiang $\mathrm{S}$, Baltimore D. RNA-binding protein Lin28 in cancer and immunity. Cancer Lett. 2016;375(1):108-13.

10. Velasco MX, Kosti A, Guardia GDA, Santos MC, Tegge A, Qiao M, et al. Antagonism between the RNA-binding protein Musashi1 and miR-137 and its potential impact on neurogenesis and glioblastoma development. RNA. 2019;25(7):768-82

11. Zhang L, Chen Y, Li C, Liu J, Ren H, Li L, Zheng X, Wang H, Han Z. RNA binding protein PUM2 promotes the stemness of breast cancer cells via competitively binding to neuropilin-1 (NRP-1) mRNA with miR-376a. Biomed Pharmacother. 2019;114:108772.

12. Palanichamy JK, Tran TM, Howard JM, Contreras JR, Fernando TR, SterneWeiler T, et al. RNA-binding protein IGF2BP3 targeting of oncogenic transcripts promotes hematopoietic progenitor proliferation. J Clin Invest. 2016;126(4):1495-511.

13. Han L, Huang C, Zhang S. The RNA-binding protein SORBS2 suppresses hepatocellular carcinoma tumourigenesis and metastasis by stabilizing RORA mRNA. Liver Int. 2019;39(11):2190-203.

14. Dong W, Dai ZH, Liu FC, Guo XG, Ge CM, Ding J, Liu H, Yang F. The RNAbinding protein RBM3 promotes cell proliferation in hepatocellular carcinoma by regulating circular RNA SCD-circRNA 2 production. EBioMedicine. 2019:45:155-67.

15. Yu G, Wang LG, Han Y, He QY. clusterProfiler: an R package for comparing biological themes among gene clusters. OMICS. 2012;16(5):284-7.

16. Kanehisa M, Goto S, Sato Y, Furumichi M, Tanabe M. KEGG for integration and interpretation of large-scale molecular data sets. Nucleic Acids Res. 2012;40(Database issue):D109-14.

17. Szklarczyk D, Morris JH, Cook H, Kuhn M, Wyder S, Simonovic M, et al. The STRING database in 2017: quality-controlled protein-protein association networks, made broadly accessible. Nucleic Acids Res. 2017;45(D1):D362-8

18. Diboun I, Wernisch L, Orengo CA, Koltzenburg M. Microarray analysis after RNA amplification can detect pronounced differences in gene expression using limma. BMC Genomics. 2006;7:252.

19. Iasonos A, Schrag D, Raj GV, Panageas KS. How to build and interpret a nomogram for cancer prognosis. J Clin Oncol. 2008;26(8):1364-70.

20. Akateh C, Black SM, Conteh L, Miller ED, Noonan A, Elliott E, Pawlik TM, Tsung A, Cloyd JM. Neoadjuvant and adjuvant treatment strategies for hepatocellular carcinoma. World J Gastroenterol. 2019;25(28):3704-21.

21. Fitzmaurice C, Allen C, Barber RM, Barregard L, Bhutta ZA, Brenner $\mathrm{H}$, et al. Global, regional, and National Cancer Incidence, mortality, years of life lost, years lived with disability, and disability-adjusted life-years for 32 Cancer groups, 1990 to 2015: a systematic analysis for the global burden of disease study. JAMA Oncol. 2017;3(4):524-48

22. Zhao L, Cao J, Hu K, Wang P, Li G, He X, Tong T, Han L. RNA-binding protein RPS3 contributes to hepatocarcinogenesis by post-transcriptionally up-regulating SIRT1. Nucleic Acids Res. 2019;47(4):2011-28.

23. Hämmerle M, Gutschner T, Uckelmann H, Ozgur S, Fiskin E, Gross $M$, et al. Posttranscriptional destabilization of the liver-specific long noncoding RNA 
HULC by the IGF2 mRNA-binding protein 1 (IGF2BP1). Hepatology. 2013; 58(5):1703-12

24. Kang H, Heo S, Shin JJ, Ji E, Tak H, Ahn S, Lee K, Lee EK, Kim W. A miR-194/ PTBP1/CCND3 axis regulates tumor growth in human hepatocellular carcinoma. J Pathol. 2019;249(3):395-408.

25. Sanduja S, Blanco FF, Dixon DA. The roles of TTP and BRF proteins in regulated mRNA decay. Wiley Interdiscip Rev RNA. 2011;2(1):42-57.

26. Brooks SA, Blackshear PJ. Tristetraprolin (TTP): interactions with mRNA and proteins, and current thoughts on mechanisms of action. Biochim Biophys Acta. 2013;1829(6-7):666-79.

27. Esteller M. Cancer epigenomics: DNA methylomes and histone-modification maps. Nat Rev Genet. 2007;8(4):286-98.

28. Kulis M, Esteller M. DNA methylation and cancer. Adv Genet. 2010;70:27-56.

29. Satyanarayana A, Manns MP, Rudolph KL. Telomeres and telomerase: a dual role in hepatocarcinogenesis. Hepatology. 2004;40(2):276-83.

30. Wong CM, Tsang FH, Ng IO. Non-coding RNAs in hepatocellular carcinoma: molecular functions and pathological implications. Nat Rev Gastroenterol Hepatol. 2018;15(3):137-51.

31. Wolin SL, Maquat LE. Cellular RNA surveillance in health and disease. Science. 2019;366(6467):822-7.

32. Gaudet P, Livstone MS, Lewis SE, Thomas PD. Phylogenetic-based propagation of functional annotations within the gene ontology consortium. Brief Bioinform. 2011;12(5):449-62.

33. Lee H, Sengupta N, Villagra A, Rezai-Zadeh N, Seto E. Histone deacetylase 8 safeguards the human ever-shorter telomeres $1 \mathrm{~B}$ (hEST1B) protein from ubiquitin-mediated degradation. Mol Cell Biol. 2006;26(14):5259-69.

34. Vaquerizas JM, Kummerfeld SK, Teichmann SA, Luscombe NM. A census of human transcription factors: function, expression and evolution. Nat Rev Genet. 2009;10(4):252-63.

35. Hölzel M, Rohrmoser M, Schlee M, Grimm T, Harasim T, Malamoussi A, Gruber-Eber A, Kremmer E, Hiddemann W, Bornkamm GW, et al. Mammalian WDR12 is a novel member of the Pes1-Bop1 complex and is required for ribosome biogenesis and cell proliferation. J Cell Biol. 2005; 170(3):367-78

36. Heo I, Joo C, Kim YK, Ha M, Yoon MJ, Cho J, Yeom KH, Han J, Kim VN. TUT4 in concert with Lin28 suppresses microRNA biogenesis through premicroRNA uridylation. Cell. 2009;138(4):696-708.

37. Kim HM, Kang DK, Kim HY, Kang SS, Chang Sl. Angiogenin-induced protein kinase B/Akt activation is necessary for angiogenesis but is independent of nuclear translocation of angiogenin in HUVE cells. Biochem Biophys Res Commun. 2007;352(2):509-13.

38. Nedumaran B, Hong S, Xie YB, Kim YH, Seo WY, Lee MW, Lee CH, Koo SH, Choi HS. DAX-1 acts as a novel corepressor of orphan nuclear receptor HNF4alpha and negatively regulates gluconeogenic enzyme gene expression. J Biol Chem. 2009;284(40):27511-23.

39. Chung KY, Cheng IK, Ching AK, Chu JH, Lai PB, Wong N. Block of proliferation 1 (BOP1) plays an oncogenic role in hepatocellular carcinoma by promoting epithelial-to-mesenchymal transition. Hepatology. 2011;54(1): 307-18.

40. Panella M, Mosca N, Di Palo A, Potenza N, Russo A. Mutual suppression of miR-125a and Lin28b in human hepatocellular carcinoma cells. Biochem Biophys Res Commun. 2018;500(3):824-7.

41. Jiang $H L$, Xu D, Yu H, Ma X, Lin GF, Ma DY, Jin JZ. DAX-1 inhibits hepatocellular carcinoma proliferation by inhibiting $\beta$-catenin transcriptional activity. Cell Physiol Biochem. 2014;34(3):734-42.

42. Pestana RC, Hassan MM, Abdel-Wahab R, Abugabal YI, Girard LM, Li D, Chang P, Raghav K, Morris J, Wolff RA, et al. Clinical and prognostic significance of circulating levels of angiopoietin-1 and angiopoietin-2 in hepatocellular carcinoma. Oncotarget. 2018:9(102):37721-32.

43. Jachimowicz RD, Beleggia F, Isensee J, Velpula BB, Goergens J, Bustos MA, Doll MA, Shenoy A, Checa-Rodriguez C, Wiederstein UL, et al. UBQLN4 Represses Homologous Recombination and Is Overexpressed in Aggressive Tumors. Cell. 2019;176(3):505-19 e522.

44. Yu Q, Gao K. CLEC4M overexpression inhibits progression and is associated with a favorable prognosis in hepatocellular carcinoma. Mol Med Rep. 2020; 22(3):2245-52.

45. Mossmann D, Park S, Hall MN. mTOR signalling and cellular metabolism are mutual determinants in cancer. Nat Rev Cancer. 2018;18(12):744-57.

46. Mihaylova MM, Shaw RJ. The AMPK signalling pathway coordinates cell growth, autophagy and metabolism. Nat Cell Biol. 2011;13(9):1016-23.
47. Karaman S, Leppänen VM, Alitalo K. Vascular endothelial growth factor signaling in development and disease. Development (Cambridge, England). 2018;145(14):dev151019.

48. Llovet JM, Montal R, Sia D, Finn RS. Molecular therapies and precision medicine for hepatocellular carcinoma. Nat Rev Clin Oncol. 2018;15(10):599616.

\section{Publisher's Note}

Springer Nature remains neutral with regard to jurisdictional claims in published maps and institutional affiliations.
Ready to submit your research? Choose BMC and benefit from:

- fast, convenient online submission

- thorough peer review by experienced researchers in your field

- rapid publication on acceptance

- support for research data, including large and complex data types

- gold Open Access which fosters wider collaboration and increased citations

- maximum visibility for your research: over $100 \mathrm{M}$ website views per year

At BMC, research is always in progress.

Learn more biomedcentral.com/submissions 